\title{
Derecho de rectificación
}

En el número 37 de nuestra revista, correspondiente al año 2016, en esta misma sección se publicaron una entrevista y una muestra de las pinturas de Américo Tísoc Monteagudo. Fueron treinta y tres páginas que pretendían homenajear al mencionado artista plástico. La introducción a la entrevista empezaba en estos términos: "Américo Tísoc Monteagudo es un pintor a tiempo completo. Vive encerrado a cal y canto en una casona de trece habitaciones, con paredes enlucidas y jardín compuesto de cactus sagrados y piedras incas. Queda frente a la plaza de Ollantaytambo, preciosa ciudad serpenteada por callejas empedradas y bullicio turístico. Dentro impera una calma de convento, apenas distraída por zumbidos de picaflores y notas clásicas de piano. Desde que habita esta casona, hace décadas, Américo empieza a trabajar todos los días con los primeros fulgores del sol...".

No obstante, contrario a nuestro propósito, el artista se ha sentido agraviado por el resultado y nos ha solicitado una rectificación por "las afirmaciones inexactas vertidas" en dicha entrevista. Como director y autor de la entrevista lamento mucho su percepción y ofrezco mis disculpas públicas. Pasé algunos días en su casa, al amparo de su aprecio, conversando y observando su quehacer cotidiano, en procura de una semblanza que presentara con respeto y admiración una vida dedicada al arte. También lamento que este episodio, registrado como un ejercicio literario, haya resquebrajado una larga amistad. 


\section{CARTA NOTARIAL}

Lima, 9 de abril del 2018

SEÑOR:

RECTOR DE LA UNIVERSIDAD DE LIMA Oscar Quezada Machiavello. Santiago de Surco - Lima.

Av. Javier Prado Este N 4600 - Urb. Fundo Monterrico Chico.

NOTARIA LOAYZA

JR. HUASCAR 1543 - JESUS MARIA

TELFS $266-0590-266.0591$

$266-0592-266.0593$

E-mail: admunstración@inotarialoayza.com

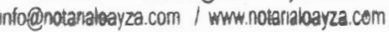
CARTANOTARIAL 329.9!1. 2018. ma............ ABR.2018

Haciendo uso del derecho contenido en el Art. 2 Inc. 7 de la Constitución Política del estado, recurro a su judicatura con profunda indignación, por la publicación que se ha realizado en la Revista Lienzo edición $N^{*} 37$, con relación a mi persona donde mi calidad profesional ha sido denostada, por el Señor Jorge Eslava de la cual es Director y Reportero.

Confiado por el prestigio de su Universidad y subyugado por encontrar en el tiempo, un amigo de juventud, que intentaba ser buen poeta y escritor, quien me propone dar a conocer mi trabajo, en dicha revista, en mayo 2016, lo acogí en mi casa taller por dos semanas, en diciembre de 2015 (sin cobro alguno) realizamos el trabajo y también se le ilevo hasta las alturas de Cachiccata para percibir el antiguo diseño del lugar, la naturaleza que nos rodeaba y en Calca a 4000 metros en Ancashmarca contemplamos la geometría que sintetiza el señorío de sus creadores, para que tenga en cuenta la relación del entorno con mi trabajo, luego espere pacientemente todo el año 2016 que me enviara el texto de la entrevista para aprobarla o no, como era el trato, no cumplió, en mayo del 2017 recién sale la revista, ahora motivado por reconocimientos a su obra ha asumido poses de gurú, con el suficiente poder de editar, tergiversar y maltratar a sus amigos, con el propósito de justificar un trabajo ajeno a la realidad, las respuestas que di a sus entrevistas durante dos semanas, han sido mutiladas burdamente (vulgarmente) por el cuchillo de un carnicero decadente y poco perspicaz, deliberadamente suprimidas las respuestas esenciales, cambios y supresiones concordadas en su supuesta entrevista con la finalidad de desacreditarme, difamarme, en vez de abocarse al arte apela a lo más fácil, la vida privada, inventando un personaje en el que no me reconozco, mucho menos pateando a cualquiera, a turistas o que mi madre era más consentidora que las demás, que no tenía ropa formal para recibir un premio, una anécdota sucedida en hospital francés la traslada al Perú, inventa un granizo 
donde nunca lo hubo o las calles del trazo inca ortogonales, para él son serpenteantes, jamás he usado overol, menos considerar un cactus como sagrado, solo la vida es sagrada.

En la Revista "Somos" del Diario El Comercio pág. 70 del 03/06/2017, se le pregunta cuál es la cualidad que admira más en una persona? Responde la integridad y que persona viva te parece despreciable? Las que abusan del poder, como Director y reportero de esta revista cultural, en dos semanas de trabajo, se ve está confundido en la búsqueda de la verdad, que implica en su libre ejercicio la honestidad e integridad, de la cual depende la justa apreciación de los hechos, no ha podido traducir mi experiencia personal, con el ánimo de apreciar mi trabajo en la pintura, como en la defensa del patrimonio arqueológico de la Nación, motivo por el que tuve conflictos siempre gracias a la incompetencia y corrupción de algunos burócratas, sobre todo del Ministerio de Cultura.

En la pregunta $N^{\circ} 35$ mi respuesta fue, que la fascinación que sentía por el estudio de la física y química del color y la luz, coincidía (años antes había estudiado el curso de teología) con mi entusiasmo por la fenomenología y energética de Theilard de Chardin, su pasión por lo absoluto, cuya famosa frase "en la escala de lo cósmico, solo lo fantástico tiene probabilidades de ser verdadero" con esta intensa motivación me esforzaba por crear plásticamente, atmosferas tridimensionales por la temperatura del color y 10 años después fui conmovido por unos cuadros del Maestro Winternitz, realizados en homenaje a Theilard, era una serie de cuadros denominada "Himno del Universo" (tema que coincidía con un pequeño ensayo que había realizado para dicho curso de Teología) y su título es "Aproximaciones: el hombre, la psicología, la religión" cuya bibliografía incluía Theilard de Chardin, Ortega y Gasset, Gustavo Jung , Herbert Read y otros; hecho que conoce bien el reportero, dueño de un ejemplar, recordando que todo eso es parte del desarrollo de mi pintura; razón por la cual el Profe como le decíamos, burlándose un poco me decía teólogo. Le conté la correspondencia que manteníamos antes de retomar mis estudios en la escuela, por cartas o teléfono, incluí una anécdota risible, porque en una de sus cartas me decía, que quiere saber de mis pinturas recientes, pero que leyendo mi carta se pregunta si mi verdadera vocación artística no está en la literatura, lo sentí casi como un golpe bajo $\mathrm{V}$ regrese inmediatamente a la escuela, donde al finalizar los estudios recibí el premio "para la mejor obra pictórica de la promoción" y no de honor como dice el reportero y jamás llamaría cachivaches al trabajo de esa época gracias a ellos me concedieron ese premio. 
No encuentro aún la razón que haya inspirado a su reportero este atentado, venganza? envidia? Para inventar un personaje sin principios, en el que no me reconozco y me obliga a defenderme, pero a través de un acto casi repugnante y tedioso para mí que es hablar de uno mismo. La falsa información que se ha descrito, la impresionante insensibilidad con que ha sido ejecutada dicha entrevista, habiéndome visto trabajar todos los días durante dos semanas, siempre con música clásica occidental y en vez de tratar lo que me concierne, ha optado por mi vida privada, esta notoria insensibilidad es porque no tiene relación directa con la obra de pintura o lugar paisajístico como tal, es un intelectual sin capacidad de reacciọn sensual ante los valores estéticos, dónde hay un buen cuadro y que hace de él un buen cuadro es lo que interesa saber, recurrir con tanta facilidad a la vida privada, detalles intrascendentes y falsos, insistiendo chabacanamente varias veces en la misma tontería, es resultado de una ignorancia preocupante en un profesor de jóvenes, que no se interesa por su trabajo y menos por la institución que representa.

Destruida la confianza, nada espiritual ni trascendente se puede esperar de un inventor mentiroso, sino sus propias lacras, sin ética ni inteligencia, no se negocia con la honra. Jamás fui egocéntrico o vanidoso, menos entre compañeros de estudio y nunca dije sentirme superior a nadie, como resalta el entrevistador.

En el programa televisivo "La función de la palabra" de Marco Aurelio Denegri, Jorge Eslava le dice "que una búsqueda trascendental es lo que busca, en cada entrevista, que sea eterna, recordada" sin embargo con esta agresión a las buenas costumbres, especie de terrorismo cultural más parece emulo del Rector Acuña.

La pregunta 55- 56 donde tratamos sobre los objetos, le explique que en mi pintura quisiera liberar el arte de la carga del mundo de los objetos, reivindicar el gozo del puro acto creador, etc, etc., parece que no entendió pero invento una pregunta y respuesta, que si me la hubiera hecho a mí, le habría respondido que en mi casa hay tantos cuadros porque es un taller de pintura.

En la intervención del escritor cusqueño Sr. Edgar Elorrieta, un escrito cuyo título original es "Retrato" y corresponde a la personalidad y obra del pintor, pero el entrevistador lo mutila casi totalmente, le cambia el nombre a "Bajo los astros" cambia relojes de arena por relojes de piedra, etc, motivo por el cual exijo la publicación del trabajo original y en su integridad. 
Ha cambiado hasta el nombre de Enrique Samanez, gran amigo desde el colegio y la escuela por Roberto Samanez, en la pregunta $N^{\circ} 28$, ha trastocado fechas en varios sucesos de mi biografía, tales como la fecha en que dejo la escuela, cuando la retomé y termino los estudios diez años después en 1988, confundiendo al lector; dado que las entrevistas fueron grabadas, exijo se me entregue una capia de las mismas como evidencia de esta grave difamación.

Finalizando quiero recordar enseñanzas de Herbert Read (Eminente estudioso del arte) sobre estas entrevistas dice: "Estos prefacios debían ser apreciativos, antes que críticos, cuando presentamos a un amigo ante un grupo de extraños, no llamamos la atención sobre la verruga de su nariz y tampoco mencionamos sus dificultades domésticas”.

Adjunto documentos probatorios, que a insistencia del entrevistador se los confié en fotocopias, los mismos que adjunto:

1. Ensayo titulado "Aproximaciones: el hombre, la psicología, la religión". Septiembre de 1978.

2. Carta de Adolfo Winternitz del 05/08/1985.

3. "Retrato" escrito original del Sr. Edgar Elorrieta.

4. Recortes del Diario El Comercio de Lima. Nobleza Inca en el Sigio XXI, 09 de septiembre del 2012.

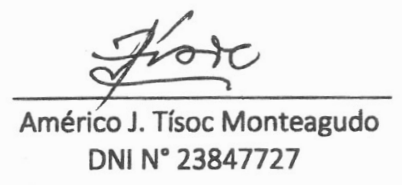


